\title{
DEMOGRAFIA E EDUCAÇÃO E COMUNICAÇÃO COMO FENÔMENOS DE SECULARIZAÇÃO? CORRELAÇÃO ENTRE OS ÍNDICES DE SEGURANÇA EXISTENCIAL E DE RELIGIOSIDADE NA EUROPA
}

- JORGE BOTELHO MONIZ1

1 Doutor em Ciência Política pela Universidade Nova de Lisboa e na UFSC - Universidade Federal de Santa Catarina. Licenciado em Ciência Política e Relações Internacionais pela FCSH/NOVA e mestre em Direito FD/NOVA. E-mail: jobomoniz@gmail.com.

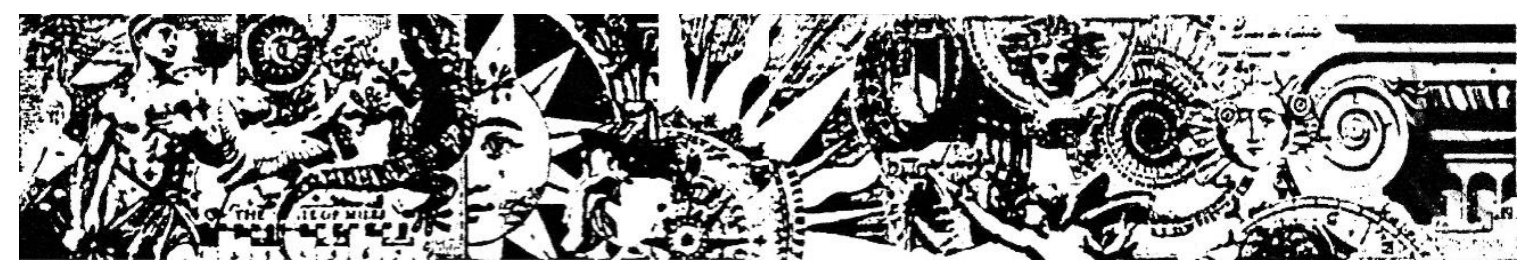

Resumo: Esta investigação quer dar resposta a dois argumentos essenciais: a ideia de que se chegou a um ponto morto no debate sobre a secularização e de que são precisas novas estratégias teóricas e empíricas para se compreenderem os efeitos dos processos da modernidade na religião. Nesse sentido, inspirando-nos nas proposições de uma das teorias mais atuais, relevantes e sistemáticas da secularização - a segurança existencial -, propomos a criação de um índice de segurança existencial que seja correlacionável com uma medida de religiosidade individual. Chegamos à conclusão de que, para o grupo de países europeus selecionado e para o período temporal examinado (1999-2015), a teoria da secularização, que assevera que as sociedades mais seguras existencialmente são menos religiosas, continua tendo validade empírica.

Palavras-chave: secularização, segurança existencial, índice, religião, demografia, comunicação. 


\title{
DEMOGRAPHY AND EDUCATION AND COMMUNICATION AS SECULARIZATION PHENOMENA? CORRELATION BETWEEN INDEXES OF EXISTENTIAL SECURITY AND RELIGIOSITY IN EUROPE
}

\begin{abstract}
This research seeks to answer two fundamental arguments: the idea that we have reached a deadlock in the secularization debate, and that we need new theoretical and empirical approaches to understand the effects of modernity's processes on religion. In order to do this and inspired by the assumptions of one of the most current, prominent and systematized theories of secularization existential security - we propose the creation of an index of existential security that can be correlated with a measure of individual religiosity. We conclude that, for the set of selected European countries and for the time period considered (1999-2015), the secularization theory, which asserts that more existentially secure societies are less religious, still has empirical validity.
\end{abstract}

Keywords: secularization, existential security, index, religion, demography, communication.

\section{DEMOGRAPHIE ET EDUCATION ET COMMUNICATION COMME PHENOMENES DE SECULARISATION? CORRELATION PARMI LES INDICES DE SECURITE EXISTENTIELLE ET DE RELIGIOSITE EN EUROPE}

Résumé: Cette recherche veut répondre à deux arguments essentiels: l'idée que nous sommes arrivés à une impasse dans le débat sur la sécularisation et que nous avons besoin de nouvelles stratégies théoriques et empiriques pour comprendre les effets des processus de la modernité sur la religion. En ce sens, en nous appuyant sur les propositions de l'une des théories les plus actuelles, pertinentes et systématiques de la sécularisation - la sécurité existentielle -, nous proposons la création d'un indice de sécurité existentielle qui soit corrélée à une mesure de religiosité individuelle. Nous arrivons à la conclusion que, pour le groupe des pays européens sélectionnés et pour la période étudiée (19992015), la théorie de la sécularisation, qui affirme que les sociétés existentiellement plus sûres sont moins religieuses, a encore validité empirique.

Mots-clés: sécularisation, sécurité existentielle, indice, religion, démographie, communication.

\section{Introdução}

Nas últimas décadas, os debates sobre religião têm-se caracterizado, por um confronto teórico entre duas narrativas sobrepostas, embora aparentemente antitéticas. Por um lado, a narrativa de uma perda de relevância social da religião, preconizada pelos defensores das teorias da secularização, na maioria cientistas sociais europeus. Por outro lado, a narrativa do regresso do (significado social do) religioso ou das religiões, maioritariamente defendido por teóricos estadunidenses.

Todavia, como nos diz Casanova (2007, p. 3), chegou-se a um "ponto morto neste debate", pois a teoria tradicional da secularização adequa-se, relativamente bem, à realidade europeia, mas não à norte-americana, enquanto a narrativa da vitalidade dos mercados religiosos (desregulados) 
é relativamente eficaz para explicar a realidade dos Estados Unidos da América, mas não a da Europa. Os teóricos afirmam ser necessária uma mudança de rumo das pesquisas sobre esse fenômeno (HALIKIOPOULOU, 2011), porque, chegados a este "beco sem saída para o estudo sociocientífico da religião" (WOHLRAB-SAHR; BURCHARDT, 2017, p. 144), o debate sobre a secularização tem-se tornado "infrutuoso" (CASANOVA, 2007, p. 1, 3).

Tendemos a concordar com essas asserções. Contudo, relembramos que, com a integração, aplicação e desenvolvimento da ideia das múltiplas modernidades de Eisenstadt (2000) no debate sobre a secularização surgiram uma série de inovações conceptuais e epistemológicas sobre o lugar do religioso no mundo. Em particular, as ideias de dessecularização (BERGER, 1999), pós-secularização (HABERMAS, 2008), múltiplas secularizações (NORRIS; INGLEHART, 2004; MARTIN, 2005; DEMERATH, 2007; CASANOVA, 2011) ou secularidades (WOHLRAB-SAHR; BURCHARDT, 2012) e secularização contextual (CASANOVA, 2007; PICKEL, 2011; BEN-PORAT; FENIGER, 2013; MONIZ, 2017a). O problema desta miríade de inovações ou renovações teóricas e conceptuais é que, segundo Pickel (2017), mantêm em suspenso uma questão que ainda não foi decidida definitivamente. Ou seja, que processos da modernidade, se é que algum, conseguem descrever as atuais mutações ou deslocações do religioso nas sociedades contemporâneas? Efetivamente, a maioria dessas conceptualizações mais recentes é sustentada cientificamente pela análise de fatores históricos, pelas reflexões de cariz sociológico e/ou filosófico ou pela descrição de fenômenos sociopolíticos. Raros têm sido os estudos que associam a dimensão teórica a uma dimensão mais empírica - estatística - que analise com rigor os desenvolvimentos (positivos ou negativos) dos fenômenos religiosos. Mesmo nos casos em que isso sucedeu (NORRIS; INGLEHART, 2004; PICKEL, 2017) os estudos basearam-se, não raras vezes, em variáveis uni ou bidimensionais, negligenciando a sistematização das várias teorias da secularização e das suas alternativas teóricas para compreender e interpretar os fenômenos de deslocação, revitalização ou declínio do religioso nas sociedades contemporâneas.

Essa análise avulsa, ainda que longitudinal, de perguntas de inquéritos de bancos de dados internacionais - por exemplo, a crença em Deus ou a frequência a serviços religiosos - não só não capta as dimensões da religiosidade (individual e difusa) contemporânea, como não examina a fundo os argumentos dos teóricos da secularização. Por conta dessa incúria, desconhecemos a existência de algum estudo que tenha procurado e que tenha logrado (como nós tentaremos) condensar esses argumentos teóricos em variáveis empíricas mensuráveis e que, além disso, as tenha contraposto a níveis multidimensionais e abrangentes de religiosidade. 
Consideramos que só através de uma tal metodologia poderemos responder à supracitada interrogação de Pickel e, assim, compreender se as teorias da secularização ou as suas alternativas teóricas são válidas para justificar as mutações do religioso, sobretudo, ao nível micro (individual).

Este trabalho se foca na teoria da segurança existencial, não só porque a consideramos uma das teorias nucleares da secularização (MONIZ, 2017b) - concomitantemente com as suas sub-teorias clássicas da racionalização, diferenciação funcional e societalização ${ }^{2}$-, mas também porque é o esforço teórico mais atual e sofisticado para entender um dos fatores-chave da modernização que explica a diminuição do significado microssocial da religião.

\section{A segurança existencial como conceito multidimensional}

A teoria da segurança existencial diz-nos, grosso modo, que as condições que as pessoas experienciam, nomeadamente nos seus primeiros anos de vida, têm um impacto profundo nos seus valores culturais. Por um lado, crescer em sociedades nas quais a sobrevivência é incerta conduz a uma forte ênfase na religião; por outro lado, o crescimento em sociedades com níveis elevados de segurança existencial reduz a relevância subjetiva da religião na vida das pessoas. Populações vulneráveis, que experienciam incertezas e riscos consideráveis nas suas vidas, consideram a religião mais importante e, por isso, participam com maior frequência e intensidade nas suas atividades cultuais ou espirituais. Conforme a vida se torna mais confortável e segura, os indivíduos tendem a encarar com maior indiferença os valores religiosos, a olhar com maior ceticismo para a crença em poderes sobrenaturais e a tornar-se menos ativos nas instituições religiosas. Assim, espera-se que, à medida que as sociedades se modernizem e se tornem, em princípio, mais seguras, a procura ou necessidade de religião seja menos intensa e frequente.

Esta teoria pode ser compreendida, segundo a própria formulação dos seus autores (NORRIS; INGLEHART, 2004), através de quatro elementos essenciais: o desenvolvimento socioeconômico, a educação e as comunicações, cuidados de saúde e a demografia. O primeiro mede, entre outros, o nível de desenvolvimento humano e a igualdade de rendimentos entre os indivíduos, sendo que, quanto maior o desenvolvimento e quanto menor a desigualdade, menor será a necessidade dos indivíduos recorrerem à religião. O segundo é baseado na ideia de que, com o aumento da formação educacional e com o maior acesso às tecnologias da informação, os

\footnotetext{
2 Para mais desenvolvimentos sobre o que designamos de teorias nucleares ou camadas internas da secularização, cf. nosso trabalho Moniz (2017b). 
indivíduos se tornam mais conhecedores do mundo e se deixam impregnar por cosmovisões mais seculares. Por consequência, passam a procurar menos o sobrenatural aquando da explicação e entendimento dos fenômenos sociais que os rodeiam. A terceira diz que, quanto mais evoluídos e democráticos forem os cuidados de saúde, menor é a necessidade de se recorrer à religião e aos seus meios não científicos para curar doenças. Provavelmente como consequência das três explicações anteriores, mas inversamente aos seus pressupostos básicos (mais desenvolvimento significa menos religião), na dimensão demografia é afirmado que mais a crescimento populacional é igual a mais empenho dos indivíduos relativamente à religião. A contrario sensu, o desenvolvimento humano conduz a mudanças culturais que reduzem a religiosidade e as taxas de fertilidade. Em suma, seguindo o modelo de Norris e Inglehart, podemos detetar, quatro dimensões internas da segurança existencial 3 .

Determinadas essas dimensões, pudemos proceder à recolha de dados (itens/indicadores) que integrassem e dessem corpo a cada dessas dimensões. Procurámos seguir o mais perto possível o modelo de Norris e Inglehart, recorrendo a cinco bancos de dados fundamentais: o World Bank Open Data, o UNDP - United Nations Development Programme, o Eurostat, a OCDE - Organização para a Cooperação e Desenvolvimento Econômico e a OMS Organização Mundial de Saúde. O primeiro disponibiliza, desde a segunda década do século XX, de forma mais sistemática, dados de 189 países. 0 trabalho estatístico é gerido por um grupo de desenvolvimento de dados que, em colaboração com a comunidade estatística internacional, coleciona, compila e atualiza uma série de bancos de dados financeiros, macroeconômicos e sectoriais. O UNDP é um programa da ONU - Organização das Nações Unidas que, desde o início da década de 1990, estuda os índices de desenvolvimento humano em cerca de 170 países e territórios. Os seus dados compreendem, no essencial, dados estatísticos sobre educação, rendimentos, pobreza ou desigualdade. Por seu turno, o Eurostat, fundado em 1953, é a divisão estatística da UE - União Europeia. O seu estudo longitudinal existe desde meados do século XX, mas tem-se solidificado e sistematizado desde o final dessa mesma centúria, focando-se, entre outros, em estatísticas sobre economia e finanças, população e condições sociais, indústria, comércio e serviços e ciência e tecnologia, essencialmente, na UE dos 28. A OCDE (iniciada em

\footnotetext{
30 estudo destas dimensões deve ainda ser associado ao axioma das tradições culturais (NORRIS; INGLEHART, 2004: 17, 218). Para os autores, a erosão dos valores, crenças e práticas religiosas é moldada por processos duradouros de segurança existencial e pelo legado cultural e pela tradição religiosa de uma determinada sociedade. Por conta da relação indelével entre o seu habitus religioso e as suas tradições culturais, quando aplicarmos o nosso modelo de correlação entre a variável dependente (religiosidade) e a independente (segurança existencial) teremos em consideração essas diferenças nos países selecionados.
} 
1948, mas oficialmente fundada em 1961) recolhe e trata, longitudinalmente (desde a década de 1950), os dados de mais de 30 países espalhados pelo mundo. Os dados estatísticos aí recolhidos cobrem diversas áreas, nomeadamente o desenvolvimento, a educação e formação, a ciência e tecnologia, as finanças ou a produtividade. Por fim, a OMS através do seu observatório de saúde no mundo, vem disponibilizando estatísticas anuais (desde 2000) sobre tópicos pertinentes para a nossa investigação. Esses dados ajudam-nos essencialmente na construção da dimensão cuidados de saúde, em particular com o recurso a indicadores sobre o acesso a água potável e sobre outras questões de higiene e saneamento.

Pela sua experiência, qualidade e rigor e pelo extenso número de investigações científicas (mas também de decisões governamentais) que baseiam os seus trabalhos nestes bancos de dados, consideramos que estas fontes são fidedignas e úteis para a criação de um índice de segurança existencial que, ulteriormente, venha a ser contraposto a um de religiosidade, permitindo-nos, assim, estabelecer correlações relativas a esta teoria da secularização.

Considerando as fontes supramencionadas, o nosso período de análise é 1999-2015. A escolha destas datas não é casual. Com efeito a sua escolha deve-se ao fato de as formas mais modernas (individualizadas e indeterminadas) de religião e a diversidade das suas expressões só terem sido estudadas, pelas ciências sociais de forma mais sistemática, nas últimas década do século XX. Ou seja, se só a partir desse período os investigadores mostraram maior sensibilidade para a difusão e diversidade das expressões religiosas modernas, isso significa que, até então, os dados estatísticos disponíveis dificilmente contemplariam dimensões da religiosidade individual que se pudessem contrapor a variáveis independentes como a segurança existencial.

Esclarecidas as questões teóricas, fontais e temporais, adaptando-as às fontes disponíveis nos bancos de dados e tentando seguir e melhorar as dimensões delineadas por Norris e Inglehart, selecionámos os seguintes indicadores para medir a segurança existencial:

- Desenvolvimento socioeconômico:

a. Índice de Desenvolvimento Humano (fonte: UNDP).

b. Índice de GINI (fonte: World Bank).

C. PIB per capita registado (fonte: World Bank).

d. População urbana ( $\%$ do total) (fonte: World Bank).

e. Proporção da população nacional em regiões predominantemente urbanas (fonte: OCDE). 
- Educação e comunicação:

a. Despesa do governo com a educação (\% do PIB) (fonte: World Bank).

b. Taxa bruta de matrícula (ensino fundamental) (fonte: UNDP).

c. Taxa bruta de matrícula (ensino médio) (fonte: UNDP).

d. População com, pelo menos, alguma educação média (fonte: UNDP).

e. Média de anos de escolaridade (fonte: UNDP).

f. Subscrições de celulares (fonte: OCDE).

g. Usuários de internet (\% da população) (fonte: UNDP).

h. Indivíduos que possuem proficiência digital geral acima do nível básico (fonte: Eurostat).

i. Famílias - aparelhos para aceder à internet: computador desktop ou portátil (\% das familias) (fonte: Eurostat).

j. Indivíduos - acesso à internet móvel: celular ou smartphone para aceder à internet (\% dos indivíduos) (fonte: Eurostat).

- Cuidados de saúde:

a. Leitos disponíveis em hospitais (por 100.000 habitantes) (fonte: Eurostat).

b. Despesa corrente com a saúde (\% do PIB) (fonte: OCDE).

c. Total do emprego nas áreas social e da saúde (fonte: OCDE).

d. Imunização infantil (fonte: UNDP).

e. Baixo peso à nascença (\% do total de nascimentos) (fonte: OCDE).

f. Mortalidade infantil (até 1 ano de vida) (fonte: OCDE).

g. Mortalidade neonatal (até 28 dias de vida) (fonte: OCDE).

h. Cobertura dos cuidados de saúde (fonte: OCDE).

i. Recursos de água potável (fonte: OMS).

j. Instalações sanitárias (fonte: OMS).

- Demografia

a. Esperança média de vida à nascença (fonte: World Bank).

b. Taxa de dependência (idosos, pessoas com 65 ou mais anos) (fonte: UNDP).

C. Crescimento populacional (fonte: World Bank).

Esta variável independente vai então ser medida por 28 indicadores, divididos por quatro dimensões da segurança existencial. Não obstante se tenha mantido o mesmo número de dimensões, aumentámos, relativamente ao trabalho de Norris e Inglehart, o número de indicadores 
que compõe cada uma. Isso se afigurou necessário, porque os autores não criam propriamente um índice de segurança existencial. Aquilo que fazem é uma análise multivariada entre cada item das suas quatro dimensões e as suas variáveis dependentes participação religiosa e frequência com que reza. Todavia, como pretendemos construir um índice que possa ser correlacionado, posteriormente, com a nossa variável dependente religiosidade, consideramos importante aprofundar algumas das dimensões citadas por Norris e Inglehart. Se na primeira mantivemos 0 mesmo número de indicadores e na última acrescentámos apenas um, na segunda dimensão juntámos mais sete itens e na terceira acrescentámos quatro. Consideramos que, deste modo, aumentando a consistência interna de cada dimensão, é possível obter resultados mais rigorosos sobre a nossa variável independente ${ }^{4} .5$

Importa sublinhar que, embora nem sempre tenhamos usado exatamente os mesmos itens para a construção de cada dimensão, o espírito e a intenção que subjazem à sua edificação foram respeitados e aprofundados. Não raras vezes os itens usados pelos autores já não se encontram disponíveis ou não fazem sentido geograficamente (para os nossos países selecionados) e teoricamente (por já serem datados) ${ }^{6}$. Por isso, tivemos de fazer algumas adaptações ao tempo e espaço que estamos analisando e aos dados disponíveis para fazê-lo. Neste contexto, é também importante enfatizar que a dimensão educação e comunicação, por ser constituída por dois elementos distintos, mas complementares, é composta por dez itens, correspondendo os cinco primeiros à esfera da educação e os cinco últimos à da comunicação.

Importa salientar que Norris e Inglehart usam subíndices, como o índice de desenvolvimento humano ou o de GINI, como indicadores que compõem as suas dimensões de análise.

\footnotetext{
${ }^{4}$ Este índice é construído a partir de diferentes bases de dados que, naturalmente, usam diferentes metodologias para medir dimensões de análise distintas. A utilização de diferentes bases de dados para compor índices é uma prática habitual, por exemplo: o Better Life Index da OCDE, o Human Development Index da UNDP, o Religious Diversity Index do Pew Research Center ou os índices de regulação governamental ou social, favoritismo ou perseguição religiosa do ARDA - Association of Religion Data Archives. A seleção de indicadores diferentes de bases de dados distintas para compor os índices é, portanto, uma prática comum e necessária. É feita em uma lógica de complementaridade (dada a habitual escassez de dados de determinadas bases de dados para compor, por inteiro, um índice) e não de preterimento de determinados indicadores face a outros

${ }^{5}$ Não precisamos de calcular o alfa de Cronbach para medir a consistência interna do nosso índice, porque as dimensões e os indicadores escolhidos são baseados nos pressupostos previamente definidos pelo estado da arte e não em dimensões e indicadores idealizados por nós. Todavia, consideramos que o seu cálculo é relevante, porquanto reforça a ideia de que esse conjunto de indicadores é internamente consistente. Seguindo os níveis de fiabilidade aceites pela academia (MARÔCO; GARCIA-MARQUES, 2006; BRITES, 2015), nomeadamente os valores de referência 0,5 e 0,6 para as ciências sociais (quanto mais perto de 1 maior a consistência da escala), o nosso índice de segurança existencial apresenta uma fiabilidade alta ou elevada $(\alpha, 869)$.

${ }_{6}^{6}$ Por exemplo, o número de pessoas infetadas pelo $\mathrm{VIH}$, em meados da primeira década do século XXI e para o nosso grupo de países, não parece ser um indicador tão relevante como era em 1997, ano no qual Norris e Inglehart recolheram esse dado.
} 
Mantivemos essa estratégia metodológica na primeira dimensão que é, precisamente, onde os autores a empregam.

\section{Proposta de composição e medição do índice de segurança existencial}

Após determinarmos as quatro dimensões e os 28 indicadores que medirão o nível de segurança existencial nos nossos países selecionados, iniciamos a construção de um índice de segurança existencial (variável independente) que nos possibilitará correlacionar a sua intensidade face à nossa variável dependente religiosidade. Isso nos permitirá testar, mais empiricamente, essa teoria da secularização.

Com efeito, desde há uns anos que vimos estudando o fenômeno religioso em um grupo de países europeus. Temos investigado os fenômenos da secularização na Áustria, Eslováquia, Espanha, Itália, Polônia e Portugal ${ }^{7}$. No entanto, houve sempre dificuldades com o conceito de religião e, sobretudo, com as formas de medir a sua centralidade na vida dos indivíduos. Por conta disso propusemos, no passado recente, a criação teórica e empírica de um índice de religiosidade 8 que servisse de variável dependente e que fosse correlacionável com variáveis independentes como a segurança existencial ${ }^{9}$.

Assim sendo, na construção deste índice seguiremos a estratégia metodológica aplicada no índice de religiosidade. Isso permitirá comparar com os mesmos instrumentos os dois índices e desenvolver um marco teórico e empírico sobre a construção de um índice de segurança existencial, algo sem precedentes no debate da secularização.

\footnotetext{
7 Tal como exige o rigor científico, a seleção deste grupo de países respeita critérios amplos e objetivos. 0 primeiro prende-se com o fato de todos os países terem separação Estado-religiões. Ou seja, um secularismo positivo ou passivo, no qual o Estado promove e permite a atividade e visibilidade das religiões no espaço público. 0 segundo concerne à sua tipologia de relacionamento Estado-religiões. Os casos de estudo estão perto do conceito de principled distance, na medida em que lhes é permitido um tratamento diferenciado das várias igrejas e comunidades religiosas. Esta tipologia é baseada na separação com lei especial, hierarquização de igrejas e liberdade religiosa. Por fim, 0 derradeiro critério foi a sua condição sociorreligiosa. Selecionámos apenas países de maioria católica apostólica romana, mas onde se têm verificado fenômenos de mutação religiosa. Em particular, com o crescimento de minorias religiosas e não religiosas e a fusão dos dois - o fenômeno dos crentes sem religião. Para mais desenvolvimentos sobre estes critérios de seleção cf. Moniz (2016).

${ }^{8} 0$ nosso índice de religiosidade é uma medida multidimensional, dividida em cinco dimensões de religiosidade intelectual, ideológica, ritual, devocional e experimental - e composta por 22 indicadores. Na construção deste índice, usámos as bases de dados mais recentes do WCD - World Christian Database, do EVS - European Values Survey e do ESS - European Social Survey e aplicámo-las ao nosso grupo de países selecionados. Os seus resultados são apresentados no gráfico 1 deste artigo, onde comparamos os níveis de religiosidade e racionalização. Para mais desenvolvimentos sobre a metodologia aplicada na construção do índice cf. (MONIZ, 2018).

${ }^{9}$ Os resultados deste índice de religiosidade são visíveis no gráfico 1.
} 
Não obstante nos baseemos no modelo de Norris e Inglehart, os autores, como denunciámos, nunca construíram propriamente um índice de segurança existencial. 0 seu trabalho, apesar de inspirador do nosso modelo, se diferencia em vários aspetos relevantes. Primeiramente, os eles não têm uma variável dependente determinada. Procuram, essencialmente, entender a religiosidade em três eixos centrais: a participação religiosa, os valores religiosos e as crenças religiosas. Esses três "indicadores de religiosidade" (NORRIS; INGLEHART, 2004: 41) são compostos, no total, por oito itens, resgatados do World Values Survey e do European Values Survey (1981-2001). Além de um modelo de medição da religiosidade como este ser criticável, nomeadamente se analisado à luz do nosso índice de religiosidade, ele não compõe uma verdadeira medida de religiosidade que permita entender, como o nosso estudo propõe, a influência da ou a correlação entre a variável dependente religiosidade e as variáveis independentes (no caso do autores: as dimensões demografia ou cuidados de saúde, entre as outras já citadas). Por conta disso, apenas conseguem ver a correlação individualizada entre esses indicadores de religiosidade (as suas variáveis dependentes) e as variáveis independentes (os itens de segurança humana, alguns dos quais já citados na nossa lista de indicadores que medem a segurança existencial) (NORRIS; INGLEHART, 2004: 62), faltando-Ihes a sua comparação global. Não obstante a sofisticação metodológica do seu trabalho, em especial através da análise multivariada baseada em quatro modelos explicativos (NORRIS; INGLEHART, 2004: 66), faltamIhes ferramentas metodológicas para entender de forma mais sustentada a eventual correlação entre a variável dependente religiosidade e a variável independente segurança existencial.

Outras tentativas de construção de um índice de segurança existencial podem ser encontradas. Apesar desses estudos não tratarem este conceito exatamente da mesma forma que Norris e Inglehart, o modelo que vamos seguir, enfatizamos a sua relevância e atualidade. Destacamos, em particular, a investigação de Lonergan, Gustavson e Carter (2000) sobre a insegurança humana. Os autores criam um índice de insegurança humana, se baseando em quatro dimensões (ambiente, economia, sociedade e instituições) compostas, individualmente, por quatro indicadores. Posteriormente, o índice é correlacionado com outro de desenvolvimento humano. Os autores concluem que existe uma forte correlação entre ambos, sugerindo que mais desenvolvimento humano conduz a uma redução da sensação de insegurança humana. Outras tentativas de medir este fenômeno foram feitas por várias organizações como a CROP Comparative Research Programme on Poverty que usa três dimensões (compostas no total por 12 indicadores) para construir um índice de segurança humana; ou o Better Life Index da OCDE 
que, no seio deste índice geral, estabelece uma dimensão de segurança baseada em apenas dois indicadores.

Esta evidente preocupação empírica de medir a (in)segurança humana ou existencial e as suas diferentes metodologias de mensuração, abrem caminho à composição do nosso índice de segurança existencial, baseado, incontornavelmente, na proposta de Norris e Inglehart. No entanto, indo mais além do que os autores, especialmente por conta do desenvolvimento teóricoempírico do conceito, patenteado no parágrafo anterior, dos dados estatísticos atualmente disponíveis e da necessidade de criar um índice multidimensional, rigoroso e, sobretudo, operacional que seja capaz de se correlacionar com a nossa variável dependente.

Assim sendo, cada variável de cada dimensão do nosso índice foi redimensionada para um intervalo de 1 a 10 (correspondentes ao valor mínimo e máximo de segurança existencial, respetivamente) e codificada consoante a escala criada para cada item. A opção por uma escala de 10 valores prende-se, principalmente, com a nossa preocupação com a maximização das diferenças entre os casos de estudo. Com efeito, eles foram selecionados com base no desenho de investigação dos sistemas mais similares, onde se comparam casos com características semelhantes. Se, por um lado, isso confere coerência à escolha dos nossos casos, favorecendo a constância das nossas variáveis; por outro lado, pode levar a variações de religiosidade e segurança existencial impercetíveis entre eles. Para se evitar uma excessiva homogeneização desses cenários e para se encontrar alguma variação, será útil o recurso a uma escala de 10 pontos, tal como Grim e Finke (2006) sugerem.

Cada um dos 28 itens do nosso modelo foi calculado através de um processo bastante simples, mas fiável. Primeiro multiplicamos por 100 o valor mínimo de cada item e depois dividimolo pelo valor máximo. Veja-se, por exemplo, o quadro 1 sobre o item PIB per capita registado.

\begin{tabular}{lcc}
\hline & \multicolumn{2}{c}{ PIB per capita registado } \\
\cline { 2 - 2 } & Valor médio bruto & Pontuação \\
\hline Áustria & 45364 \\
Itália & 36057 \\
Eslováquia & 14557 \\
Espanha & 30173 \\
Polónia & 11188 \\
Portugal & 21899 \\
\hline Fonte: World Bank (1999-2015) & \\
Valores arredondados às unidades & \\
\hline
\end{tabular}

Quadro 1 - Exemplo de medição do item: PIB per capita registado. Fonte: compilação do autor, considerando as fontes já citadas. 
Aqui o vb (valor médio bruto mais baixo) dos países selecionados é 11.188 e o va (valor médio bruto mais alto) 45.364. Aplicando a fórmula: $11.188 \times 100$ é igual a 1.118 .800 que dividido por 45.364 dá o resultado aproximado de 24,66. A diferença entre esse valor $(24,66)$ e 100 corresponde à percentagem de $75,34 \%$ que separa o vb e 0 va. A fórmula é, como frisámos, bastante simples:

$$
X=\frac{v b \times 100}{v a}
$$

Para nos assegurarmos que 0 valor de $X(75,34 \%)$ coincide com a diferença exata entre va e vb, procedemos a outro cálculo $[(X \div 100) x$ va]. Aqui o valor (médio bruto) é de aproximadamente 34.176 o que corresponde exatamente à diferença de $75,34 \%$ que dista entre 0 va e o vb. Obtido o valor de $X$ iniciamos o processo de codificação.

Sublinhamos que no quadro 1 se consegue abarcar a totalidade do nosso período temporal de análise. Contudo, pela falta de dados disponíveis, isso nem sempre sucedeu quando analisámos outros indicadores. Os valores médios brutos da tabela correspondem à média aritmética simples de cada item de cada país ${ }^{10}$. Depois, codificámos cada um desses valores através da nossa escala de padronização de 1 a 10, observável no quadro $2^{11}$.

\begin{tabular}{lcc}
\hline & \multicolumn{2}{c}{ PIB per capita registado } \\
\cline { 2 - 3 } & Valor médio bruto & Pontuação \\
\hline Áustria & 45364 & 10 \\
Itália & 36057 & 8 \\
Eslováquia & 14557 & 3 \\
Espanha & 30173 & 7 \\
Polónia & 11188 & 3 \\
Portugal & 21899 & 5 \\
\hline Escala de normalização $1-10: 1-5000=1$ ponto; $5001-10000=2$ pontos; $10001-15000=3$ pontos; \\
15001-20000 $=4$ pontos; $20001-25000=5$ pontos; $25001-30000=6$ pontos; \\
30001-35000 $=7$ pontos; $35001-40000=8$ pontos; $40001-45000=9$ pontos; $45001 »=10$ pontos \\
Fonte: World Bank $(1999-2015)$ \\
Valores arredondados às unidades
\end{tabular}

Quadro 2 - Exemplo de pontuação do item: PIB per capita registado. Fonte: compilação do autor, considerando as fontes já citadas.

10 O nosso cálculo foi o seguinte: $(34902+36181+36801+36838+36730+37070+37239+37872+38237+$ $37585+35363+35849+35994+34885+33887+33616+33912) \div 17$. A média é de 36.057 .

${ }_{11} \mathrm{Na}$ construção deste índice tivemos alguns desafios, nomeadamente a existência de valores negativos, por exemplo no item crescimento populacional; mas também o fato de nem sempre os valores mais altos corresponderem a pontuações mais elevadas, como sucede, por exemplo, no item índice de GINI. Essas questões foram resolvidas através da inversão dos valores das pontuações face aos médios brutos, de modo a que a menor adesão à dimensão negativa da segurança existencial possa indicar maior segurança existencial. 
No quadro $20 \mathrm{vb}$ foi codificado com 3 pontos e 0 va com 10 pontos. A diferença de 7 pontos aproxima-se da distância percentual real entre os dois (cerca de 75\%). 0 mesmo foi feito para os valores intermédios, i.e., aqueles que não são nem o vb nem o va. Repetimos que, embora os valores das pontuações finais não sejam sempre perfeitos, eles correspondem normalmente à proporção da diferença entre os valores brutos de cada indicador. As diferenças proporcionais, existindo, para cima ou para baixo, são sempre muito baixas, nunca ultrapassando os $10 \%$.

Aplicada esta metodologia para cada indicador da segurança existencial, codificámos todos os seus itens. Vejamos o quadro 3.

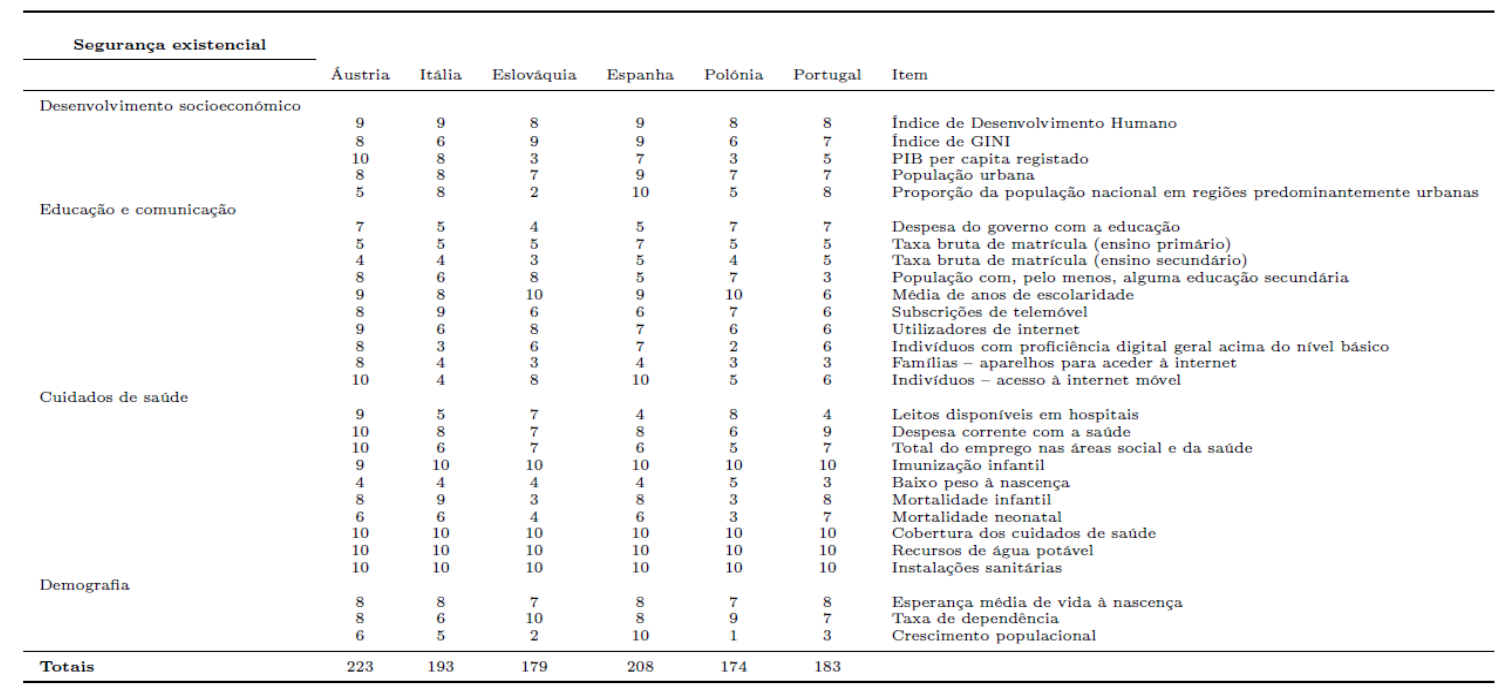

Quadro 3 - Codificação dos itens da segurança existencial em todas as dimensões. Fonte: Fonte: compilação do autor, considerando as fontes já citadas.

O máximo de pontos que cada país pode atingir, para o conjunto destes 28 indicadores, é de 280. Quanto mais perto desse valor, maior o índice de segurança existencial. O quadro 3 mostra que Áustria e Espanha são os países com maior taxa absoluta de segurança existencial. O primeiro surge destacadamente com 223 dos 280 pontos possíveis e o segundo com 208. A Itália encontrase numa posição intermédia, acumulando 193 pontos. Os três países com pior desempenho ao nível da segurança existencial são, por ordem decrescente, Portugal (183 pontos), Eslováquia (179 pontos) e, em último lugar, Polônia (174 pontos). As diferenças no índice de segurança existencial não parecem muito significativas. Com efeito, a distância entre o primeiro classificado (Áustria) e o último (Polônia) é pouco maior do que 20\% e a diferença proporcional sequencial entre países nunca ultrapassa os 7,5\%12. A proximidade entre os níveis de segurança existencial no conjunto dos nossos países, mesmo através da aplicação de uma metodologia de maximização

12 Para ser mais exato, a diferença é respetivamente de 21,97\% e de 7,21\% (a maior distância proporcional entre países é entre Espanha e Itália). 
das diferenças, pode querer dizer que teremos dificuldades em entender a presença duma correlação (positiva ou negativa) entre esta variável independente e a variável dependente religiosidade.

Visto que nenhuma das quatro dimensões da segurança existencial é, segundo o estado da arte, predominante, optámos por analisá-las e medi-las como se tivessem o mesmo peso. Assim sendo, cada dimensão da segurança existencial, independentemente do número de indicadores que a constituam, será calculada com o mesmo peso (25\%). Através do cálculo da média aritmética simples de cada dimensão obtivemos os valores observáveis no quadro 4.

\begin{tabular}{lcccccc}
\hline & \multicolumn{5}{c}{ Segurança existencial } \\
\cline { 2 - 7 } & Áustria & Itália & Eslováquia & Espanha & Polónia & Portugal \\
\hline Desenvolvimento socioeconómico & 8.0 & 7.8 & 5.8 & 8.2 & 6.0 & 6.8 \\
Educação e comunicação & 7.5 & 5.7 & 5.9 & 6.5 & 5.7 & 5.3 \\
Cuidados de saúde & 8.6 & 7.8 & 7.2 & 7.6 & 7.0 & 7.8 \\
Demografia & 7.3 & 6.3 & 6.3 & 8.7 & 5.7 & 6.0 \\
\hline Médias & 7.9 & 6.9 & 6.3 & 7.7 & 6.1 & 6.5 \\
\hline
\end{tabular}

Quadro 4 - Médias aritméticas simples de cada dimensão da segurança existencial. Fonte: compilação do autor, considerando as fontes já citadas.

Não obstante a alteração nos valores finais, a classificação entre os países, verificada no quadro 4, não se alterou. Todavia, as diferenças proporcionais aumentaram. Por exemplo, a diferença entre Áustria e Polônia passou para 22,5\% e a distância entre Espanha e Itália passou para 10,7\%. Tendo em consideração que as diferenças brutas entre os países selecionados não eram muito elevadas, o aumento das diferenças entre eles ajuda na definição de intervalos/níveis de classificação entre os países. Deste modo, estabelecemos cinco níveis de segurança existencial: entre 1,0 e 2,9 - muito baixa; entre 3,0 e 4,9 - baixa; entre 5,0 e 6,9 - média (casos da Polônia, Eslováquia, Portugal e Itália, por esta ordem crescente); entre 7,0 e 8,9 - alta (casos da Espanha e da Áustria, por esta ordem crescente); e entre 9,0 e 10 - muito alta. Nenhum dos países se encontra nos extremos desta classificação da segurança existencial. No entanto, a Áustria é o país com a maior pontuação na variável independente e a Polônia o com menor pontuação. Outra característica evidente é o fato de quatro países se encontrarem no mesmo nível (médio) de segurança existencial. Isto dificulta, tal como o quadro 3 já denunciava, a percepção das diferenças entre os países. Ainda assim, podemos destacar a existência de dois grupos distintos: os casos austríaco e espanhol, altamente seguros existencialmente, e os restantes, com índices de segurança existencial relativamente mais baixos, destacando-se aí, pelo valor de segurança existencial praticamente de nível alto, a Itália. 
O exame individual das dimensões da segurança existencial, mostram que a Áustria é, destacadamente, o país mais seguro existencialmente nas dimensões educação e comunicação e cuidados de saúde. A Espanha é o mais seguro existencialmente nas duas restantes dimensões: desenvolvimento socioeconômico e, de modo destacado, na dimensão demografia. Por seu turno, a Polônia é apenas o menos seguro existencialmente nas dimensões cuidados de saúde e demografia e ex aequo com a Eslováquia na dimensão educação e comunicação. Em nenhuma das dimensões da segurança existencial qualquer país apresenta um nível muito alto ou muito baixo. Apenas nas dimensões cuidados de saúde e demografia, Áustria e Espanha se aproximam, respetivamente, da categoria muito alta. Portugal destaca-se pelo baixo nível de segurança existencial na dimensão educação e comunicação, sendo o único país que se encontra, numa determinada dimensão da segurança existencial, mais perto de ter um índice considerado baixo.

Resumidamente, Áustria e Espanha são, respetivamente, os países mais seguros existencialmente, reunindo, entre si, 21 indicadores que se encontram no intervalo de segurança existencial muito alta, aglomerando-se, em particular, nas dimensões desenvolvimento socioeconômico e cuidados de saúde. Isso representa $45 \%$ do total de itens de segurança existencial muito alta. A maioria dos países tem, pelo menos, quatro indicadores de categoria muito alta na dimensão cuidados de saúde, nomeadamente nos itens: cobertura dos cuidados de saúde, recursos de água potável, instalações sanitárias e imunização infantil. Os países com menor índice de segurança existencial são a Polônia e a Eslováquia, concentrando 16 itens de categoria baixa ou muito baixa, nomeadamente nas dimensões educação e comunicação e cuidados de saúde, possuindo resultados relativamente baixos em indicadores como a mortalidade infantil e neonatal.

\section{Correlação entre segurança existencial e religiosidade}

Após obtermos os índices de segurança existencial para os países selecionados, comparamo-os com o índice de religiosidade - a nossa variável dependente. Aqui queremos testar 0 argumento que diz que a segurança existencial tem efeitos, tendencialmente, negativos na religiosidade. Ou seja, a maiores taxas de segurança existencial deverão corresponder menores taxas de religiosidade. Veja-se o gráfico 1. 


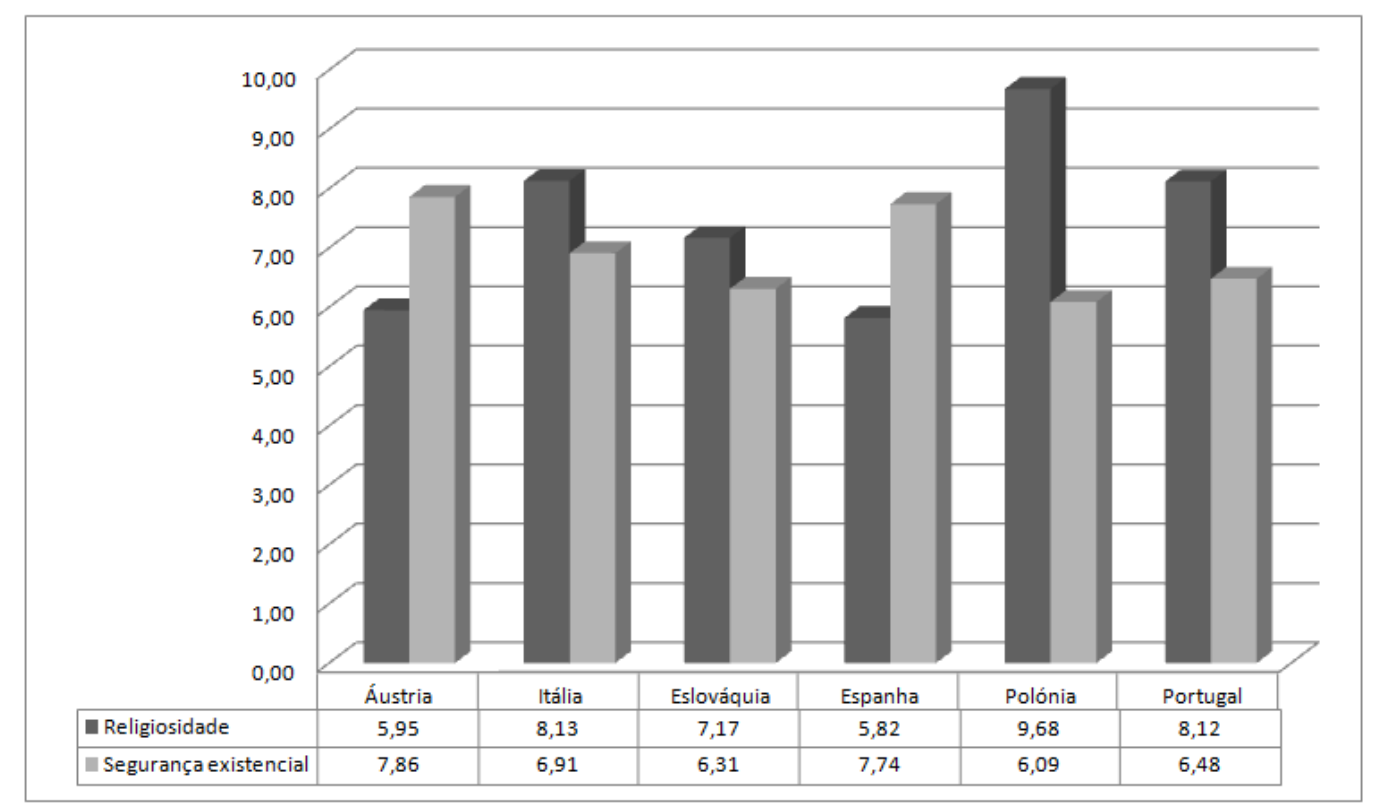

Gráfico 1 - Colunas com a relação entre os níveis de religiosidade e de segurança existencial. Fonte: compilação do autor, considerando as fontes já citadas.

O caso polonês, o mais religioso do conjunto, obtém a pontuação destacadamente menor na variável independente - segurança existencial. Concomitantemente, os países com índice de religiosidade mais baixa do conjunto, Espanha e Áustria, apresentam os níveis de segurança existencial mais altos. Por um lado, isso parece ir ao encontro da teoria da secularização que defende, como vimos, que mais segurança existencial significa menos religiosidade. Por outro lado, essa teoria não pode ser totalmente corroborada se considerarmos os outros países selecionados. De fato, Portugal e Itália, países mais religiosos do que a Eslováquia, apresentam índices de segurança existencial mais altos. Além disso, o caso italiano, tangencialmente mais religioso do que o português, apresenta, à semelhança do que sucede entre Áustria e Espanha, um índice de segurança existencial relativamente mais elevado, quase de nível alto na nossa classificação, não permitindo comprovar inteiramente esta teoria da secularização. Ainda que a análise micro, às décimas e centésimas, não permita corroborar completamente o argumento da secularização que diz que cenários mais seguros existencialmente são, em princípio, menos religiosos, o exame macro parece apontar para uma correlação negativa entre as duas variáveis. Todavia, para atestarmos isso com mais detalhe, analisemos o gráfico 2.

No gráfico 2 exploramos a relação entre os valores do índice de religiosidade (eixo Y) e os do índice de segurança existencial (eixo X). A posição relativa dos países selecionados mostra- 
nos, tal como Norris e Inglehart demonstraram, que existe uma correlação negativa forte ${ }^{13}$ e estatisticamente significativa entre as duas variáveis $(r(6)=-0,855 ; p<0,05)^{14}$. Ou seja, a segurança existencial contribui para a explicação da variação (negativa) da religiosidade $(85,5 \%)$, considerando os países selecionados e a metodologia empregue.

Com efeito, a análise dos quadrantes do gráfico 2 mostram, tal como as colunas do gráfico 1 já denunciavam, uma forte correlação negativa entre as duas variáveis. Os três países mais religiosos - Polônia, Itália e Portugal - estão no quadrante 1 (mais religiosidade e menos segurança existencial), enquanto os países menos religiosos se encontram no quadrante 4 (menos religiosidade e mais segurança existencial). Esta categorização por quadrantes está em linha com os pressupostos da teoria da secularização relativamente à segurança existencial: a existência de maior segurança existencial parece estar negativamente correlacionada com os níveis de religiosidade. Sublinhamos ainda dois elementos do gráfico 2. Primeiramente, o quadrante 2 (mais segurança existencial e mais religiosidade) está vazio, algo que ajuda a corroborar a teoria de Norris e Inglehart; ou seja, a existência de maior segurança existencial não parece conduzir a maiores índices de religiosidade. Em segundo lugar, a Eslováquia surge como um caso desviante ao modelo da secularização. 0 caso eslovaco surge no quadrante 3 (menos religiosidade e mais segurança existencial), não se encontrando em linha com qualquer outro dos países analisados. Em suma, o gráfico 2 ajuda a corroborar a teoria da secularização desenvolvida por Norris e Inglehart. Por um lado, confirma que quanto mais seguros existencialmente são os países menos religiosos tendem a ser (quadrantes 1 e 4). Por outro lado, não mostra qualquer efeito positivo da segurança existencial nos níveis de religiosidade individual (quadrante 2).

\footnotetext{
13 Neste campo, seguimos a seguinte classificação padronizada: 0: ausência de correlação; +/- 10 - 0,25]: muito fraca; +/- ]0,25 - 0,40]: fraca; +/- ]0,40 - 0,60]: moderada; +/- ]0,60 - 0,75]: moderada forte; +/- ]0,75 - 0,90]: forte; +/- ]0,90 - 1[: muito forte; +/- 1: correlação perfeita. Cf. (Brites, 2015; Marôco, 2018; Marôco \& Garcia-Marques, 2006).

$14 \mathrm{O}$ valor exato do nível de significância é ,030. 


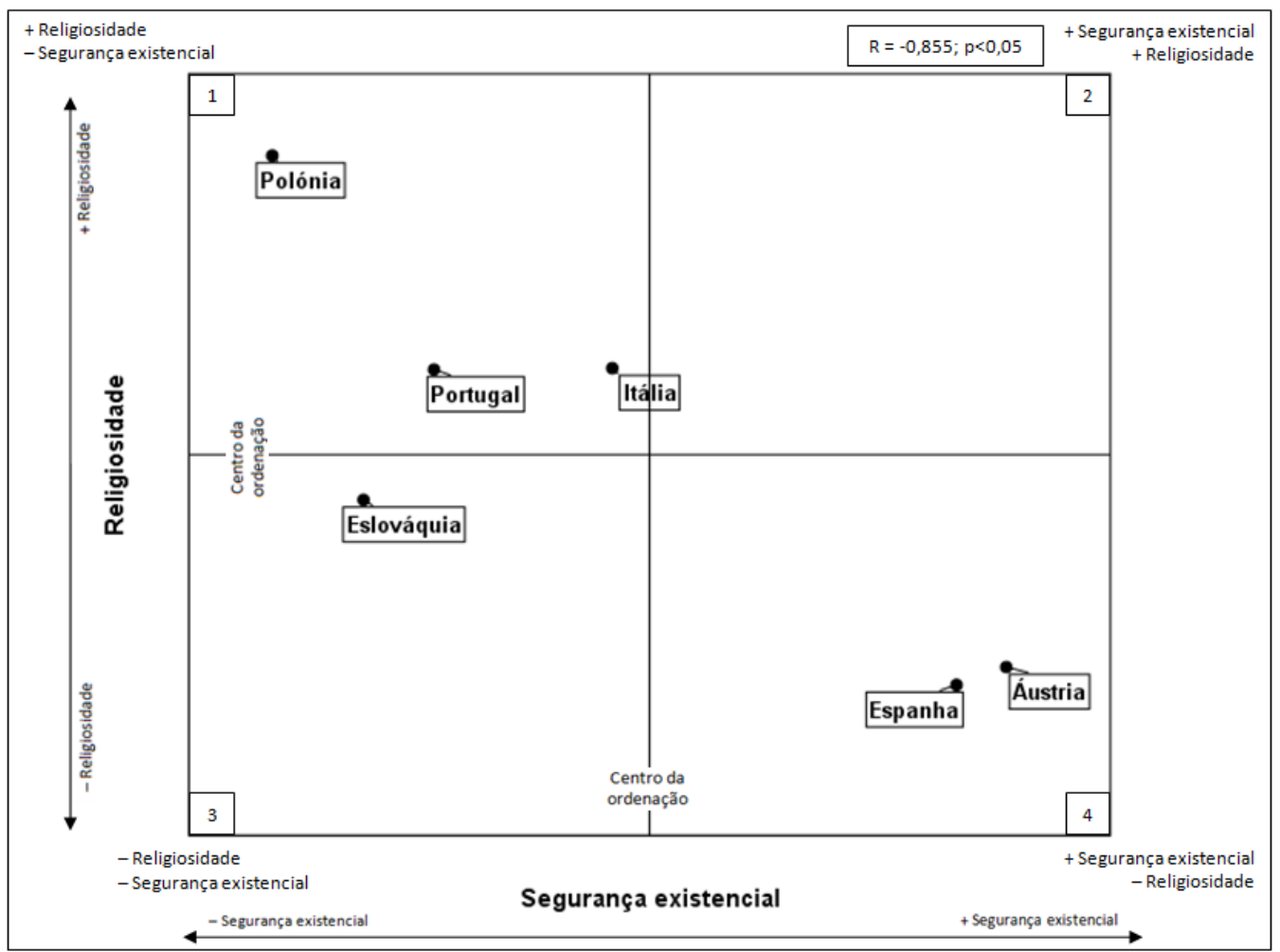

Gráfico 2 - Religiosidade vs. Segurança existencial (posição relativa dos países na respetiva ordenação). Fonte: compilação do autor, considerando as fontes já citadas.

Os intervalos classificativos, determinados após a análise do quadro 4, ajudam-nos a entender que os países com nível de segurança existencial alta são os únicos que se encontram no quadrante 4. Os restantes países que possuíam níveis médios de segurança existencial estão todos, à exceção da Eslováquia, no quadrante 1. Existe, portanto, um padrão fácil de descortinar: mais segurança existencial é igual a menos religiosidade e menos segurança existencial significa mais religiosidade. Essa tendência seria ainda mais forte se, mais uma vez, retirássemos o caso eslovaco. Assim, obteríamos uma correlação negativa muito forte entre segurança existencial e religiosidade, praticamente perfeita, sendo estatisticamente significativa $(r(5)=-0,975 ; p<0,01)^{15}$.

Atestada a correlação negativa forte, ou muito forte se excluíssemos a Eslováquia, entre as duas variáveis, é interessante ver se alguma das dimensões internas da segurança existencial tem uma correlação particularmente mais forte com a variável dependente. Observemos o quadro 5. 


\begin{tabular}{lcccc}
\hline Religiosidade & \multicolumn{4}{c}{ Segurança existencial } \\
\cline { 2 - 5 } & Desenvolvimento socioeconómico & Educação e comunicação & Cuidados de saúde & Demografia \\
\hline Correlação de Pearson &,- 641 &,$- 755^{*}$ &,- 597 &,$- 869^{*}$ \\
Sig. (bilateral) &, 170 &, 083 &, 211 &, 025 \\
$\mathrm{~N}$ & 6 & 6 & 6 & 6 \\
\hline \hline
\end{tabular}

Quadro 5 - Correlações entre a religiosidade e as dimensões da segurança existencial ${ }^{16}$ *As correlações são significativas no nível 0,10 (bilateral). Fonte: compilação do autor, considerando as fontes já citadas.

O quadro 5 permite-nos verificar que as dimensões demografia $(r(6)=-.869 ; p<0,05)$ e educação e comunicação $(r(6)=-.755 ; p<0,10)$ são as únicas que têm uma correlação negativa forte com a religiosidade, sendo estatisticamente significativas. As dimensões cuidados de saúde $(r(6)=-.597 ; p>0,10)$ e desenvolvimento socioeconômico $(r(6)=-.641 ; p>0,10)$ apresentam apenas uma correlação moderada e moderada forte, respetivamente, com a variável dependente, não sendo estatisticamente significativas.

Por um lado, as nossas correlações estão em sintonia com os dados do estudo de Norris e Inglehart, estando até mais forte e negativamente correlacionadas com a religiosidade (entre .60 e -.87) do que aquilo que os autores tinham detetado (entre -.40 e -.74). Por outro lado, contrariamente à opinião dos autores de que todos os indicadores de segurança existencial "se correlacionam forte e significativamente com as formas de religiosidade" (Norris \& Inglehart, 2004: 61), estamos longe de declarar com tanta assertividade, e mesmo com as nossas correlações mais altas, que as dimensões desenvolvimento socioeconômico ou cuidados de saúde têm um forte valor preditivo nos níveis de religiosidade, em especial se comparadas com as outras duas dimensões. Ainda assim, estas duas dimensões com menor correlação com a religiosidade parecem estar em consonância com a sua teoria. Ou seja, o desenvolvimento ou a "igualdade socioeconômica tem um impacto [negativo] na prioridade dada aos valores e às crenças religiosas" (Norris \& Inglehart, 2004: 65-67). Em contextos de maior desenvolvimento socioeconômico, tal como na Áustria ou Espanha, as crenças religiosas parecem ter uma tendência decrescente. Contudo, na Itália, um país com nível igualmente alto de desenvolvimento socioeconômico, esse efeito minguante não é visível. A dimensão cuidados de saúde deveria também ter, segundo os

\footnotetext{
${ }^{16}$ Dada a pequena dimensão da nossa amostra, apenas seis países, consideraremos significativas as correlações que tenham um intervalo de confiança de até $90 \%: p<0,10$. Ainda que procuremos sempre dar maior ênfase às correlações com intervalos de confiança menores, nomeadamente àquelas dentro do valor convencionado de $95 \%, p$ $<0,05$, pela nossa pequena dimensão amostral, pelo foco exploratório deste trabalho, um limite de referência $p<0,10$ pode sugerir um efeito significativo que deverá ser alvo de maior aprofundamento futuro. Todavia, devemos sublinhar que, mesmo que algumas das dimensões da segurança existencial não sejam estatisticamente significativas (mesmo ao nível $p<0,10$ ), todas serão consideradas para efeitos da nossa análise. Isso se deve ao fato de, em um trabalho de ciências sociais como este, haver necessidade de testar todas as dimensões citadas pelos teóricos da segurança existencial.
} 
autores, efeitos negativos na religiosidade. Isso sucederia, porque a ausência desses cuidados básicos está normalmente associada a situações de precariedade, insegurança e imprevisibilidade que "levam muitas pessoas a enfatizar a religião" (NORRIS; INGLEHART, 2004: 64). A ausência de cuidados de saúde ou a sua precariedade deveria, segundo o argumento, significar uma maior enfatização da religião. Não obstante estejamos cientes da proximidade entre os valores na nossa dimensão cuidados de saúde e das posteriores dificuldades de categorização dos países, os nossos dados não nos permitem corroborar tão afirmativamente que melhores cuidados de saúde tendem a significar menos religião. Por exemplo, Espanha, o país menos religioso do conjunto, tem resultados mais baixos nesta categoria da segurança existencial do que dois dos países mais religiosos: Itália e Portugal.

Onde a teoria de Norris e Inglehart parece, efetivamente, ter maior ressonância nos nossos dados é nas dimensões educação e comunicação e demografia. A primeira baseia-se na premissa weberiana de que mais educação leva ao crescimento das perspectivas racionais do mundo e que, consequentemente, a secularização deve ter maiores impactos na população com mais formação. Em geral, Norris e Inglehart (2004: 27) defendem que "as pessoas com menos educação e literacia [...] serão mais religiosas", ainda que afirmem que esta não é uma tendência inevitável. Complementarmente ao fenômeno educativo, a comunicação cria "gradualmente um público mais informado e consciente politicamente" (NORRIS; INGLEHART, 2004: 16). Para os autores, isso é relevante, porque as mensagens culturais difundidas pela mídia "podem turvar as perceções dos indivíduos sobre as normas e práticas religiosas adequadas" (NORRIS; INGLEHART, 2004: 76). Assim sendo, quanto mais educados e informados forem os indivíduos, menor deverá ser o seu nível de religiosidade. Com efeito, os efeitos negativos previsíveis desta dimensão da segurança existencial na nossa variável dependente são, como vimos, corroborados no nosso estudo. Mesmo que a sua ordem esteja trocada, os três países mais religiosos são os que apresentam menores índices de educação e comunicação. Inversamente, os três países menos religiosos são os que têm maiores taxas de educação e comunicação. Isso ajuda a explicar por que motivo no nosso estudo a dimensão educação e comunicação está tão negativamente correlacionada com a religiosidade.

A dimensão demografia é, porém, aquela que tem maior poder preditivo sobre a religiosidade. No nosso estudo, bem como no de Norris e Inglehart, ela se destaca por ser a hipótese mais fortemente correlacionada com a religiosidade. No desenvolvimento da sua teoria, os autores chegam inclusive a elaborar uma hipótese demográfica (NORRIS; INGLEHART, 2004: 22,231 ) por meio da qual afirmam que as taxas de fertilidade estão "sistematicamente ligadas à 
força da religiosidade" (NORRIS; INGLEHART, 2004: 29), esperando que os países com maiores índices de religiosidade tenham muito maior crescimento populacional do que os mais secularizados. Enquanto essas sociedades ditas seculares, mais ricas, produzem menos crianças e investem mais (educativa ou profissionalmente) em cada indivíduo, as sociedades mais orientadas por valores tradicionais enfatizam mais os laços entre pais e filhos e família, rejeitando fortemente o divórcio, o aborto ou a homossexualidade. Os sistemas culturais dessas sociedades podem variar, mas, no geral, encorajam as pessoas a produzir mais crianças.

Em Norris e Inglehart, há, a respeito da dimensão demografia, uma inversão da lógica da secularização. Enquanto as teorias da secularização, bem como as outras dimensões da segurança existencial, advogam que mais desenvolvimento - ou seja, mais educação e comunicação, mais desenvolvimento socioecônomico ou melhores cuidados de saúde - significa menos religião, na dimensão demografia, maior segurança demográfica (i.e., maior esperança média de vida ou maior crescimento populacional) é sinônimo de maiores índices de religiosidade. Ora, a nossa investigação, mediante o conjunto dos países analisados, não permite corroborar essa tese. Os nossos resultados mantêm-se em linha com as teorias da secularização, em particular com o argumento geral da segurança existencial, porquanto mostra, claramente, que a maior segurança existencial ao nível demográfico corresponde menor religiosidade. Ou seja, mais desenvolvimento ou segurança demográfica significa menos religiosidade.

O nosso estudo diz que a demografia, entendida à maneira de Norris e Inglehart, ajuda a prever praticamente $87 \%$ da variação negativa na religiosidade. Com efeito, se analisássemos esta dimensão através de quadrantes similares aos do gráfico 2, poderíamos verificar que os três países mais religiosos (Polônia, Itália e Portugal) se encontravam no quadrante 1 correspondente aos casos mais religiosos e simultaneamente menos seguros demograficamente. Por seu turno, os países menos religiosos, Espanha e Áustria, estariam no quadrante 4, concernente aos casos menos religiosos, mas com maior segurança demográfica.

Resumidamente podemos dizer que a segurança existencial está fortemente correlacionada com a religiosidade. $A$ isso não deve ser alheio o fato de ela ser a mais recente das teorias da secularização, utilizando métodos e softwares estatísticos que the permitem, contrariamente aos meios de investigação das décadas de 1960-70, uma aferição mais fácil, exata e global dos dados recolhidos e das suas correlações. A correlação entre segurança existencial e religiosidade é muito negativa. Ou seja, a maior desenvolvimento socioeconômico, melhores cuidados de saúde, melhores níveis de educação e comunicação e maior desenvolvimento demográfico, correspondem menores índices de religiosidade. Esse efeito negativo é, 
particularmente, visível nas duas últimas dimensões. Destacamos a dimensão demografia, pelo fato de ser o maior preditor da variação na religiosidade e pelo fato de, contrariamente ao que Norris e Inglehart previam, pelo menos para o conjunto dos países selecionados, ter uma correlação negativa forte com a religiosidade.

\section{Comentário final}

O nosso estudo permitiu-nos chegar a três conclusões essenciais. Primeira e principalmente ajudou-nos a entender que, para o conjunto dos países analisados e através da metodologia aplicada, a teoria da secularização, que diz que as sociedades mais seguras existencialmente são menos religiosas, tem validade empírica. Com efeito, os nossos dados mostram que a segurança existencial explica cerca de $86 \%$ da variação (negativa) na religiosidade. Isto é, a segurança existencial tem, em todas as suas dimensões, um impacto negativo na religiosidade. As proposições de Norris e Inglehart sobre o modo como a segurança existencial, por meio das suas várias dimensões, tende reduzir as ameaças de sobrevivência que são comuns nas sociedades, aumentando um sentimento de segurança que reduz necessidade de apelo à religião, têm portanto ressonância empírica.

O segundo ponto é o fato de a educação e comunicação e a demografia, serem as dimensões que mais impacto (negativo) têm na religiosidade. A primeira explica $76 \%$ da sua variação negativa, enquanto a segunda explica cerca de $87 \%$. Na dimensão educação e comunicação isso pode ser explicado pelo fato de a literacia e o conhecimento do mundo, pela disseminação de uma diversidade de ideias concorrentes ou contrárias às religiosas, minarem as estruturas de plausibilidade das crenças religiosas, nomeadamente das tradicionais (mais ritualizadas e institucionalizadas). Na dimensão demografia isso pode ser justificado pelo fato de a redução das ameaças existenciais e a consequente melhoria das condições de vida humana reduzirem, no geral, a frequência com as pessoas sentem necessidade de recorrer às explicações, práticas e ao auxílio religioso. A religião tende a ser encarada, nestas condições típicas de sociedades muito seguras existencialmente, obsoleta e implausível.

Por último, o nosso trabalho provou que é mais recompensador repensar, rever ou atualizar as teorias da secularização, à luz da realidade social contemporânea, do que abandonálas. Ou seja, por oposição aos críticos da secularização que admitem largar totalmente o modelo da secularização ou mudar a direção das suas pesquisas, por conta do acúmulo de críticas aos seus pressupostos teóricos e empíricos, consideramos que a secularização ainda nos oferece um 
quadro útil para a perceção da situação religiosa nas sociedades modernas, nomeadamente nas europeias, e, por isso, as suas proposições não devem ser descartadas levemente.

No nosso ver, este estudo é apenas um primeiro passo nesse sentido. Será ainda necessário aumentar as bases de dados disponíveis e, por consequência, refinar os modelos de construção de índices. Será preciso estudar outras variáveis independentes relevantes, como as teorias clássicas (racionalização, diferenciação funcional e societalização) da secularização. Será fundamental explorar novas grelhas analíticas, como as migrações internacionais, a diversidade cultural ou o terrorismo. Será inevitável examinar diferentes contextos regionais, englobando mais países (cuja comparação se justifique e seja cientificamente relevante) nas análises empíricas. No fundo, como nos disse profeticamente Berger (2014), será necessário estudar os vários altares da modernidade, religiosos ou não religiosos, e entender o paradigma (mutável e que tanto pode significar revitalização, declínio ou transformação) da religião nas sociedades hodiernas. Esses são, portanto, os reptos que deixamos aos cientistas sociais que estejam tão engajados quanto nós em entender os efeitos (positivos ou negativos) dos processos da modernidade na religiosidade.

\section{Referências}

BEN-PORAT, Guy; FENIGER, Yariv. Unpacking secularization: Structural changes, individual choices and ethnic paths. Ethnicities, v.14, n.1, 91-112, 2014.

BERGER, Peter. The Desecularization of the World, a Global Overview. In: The Desecularization of the World: Resurgent Religion and World Politics. Berger, Peter (ed.). Michigan: Grand Rapids, 1999.

BERGER, Peter. The Many Altars of Modernity: Toward a Paradigm for Religion in a Pluralist Age. Boston/Berlim: De Gruyter, 2014.

BRITES, Rui. Análise de dados com IBM SPSS®: Mix essencial para relatórios profissionais e teses académicas. Módulo I - Básico, Lisboa: ISEG, 2015.

CASANOVA, José. Reconsiderar la Secularización: Una perspectiva comparada mundial. Revista Académica de Relaciones Internacionales, n.7, 1-20, 2007.

CASANOVA, José. The secular, secularizations, secularisms. In: Rethinking Secularism. Calhoun, Craig; Juergensmeyer, Mark; Antwerpen, Jonathan Van (eds.). Nova lorque: Oxford University Press, 2011. 
DEMERATH, Jay. Secularization and Sacralization, Deconstructed and Reconstructed. In: The Sage Handbook of the Sociology of Religion. Beckford, James; Demerath, Jay (eds.). Londres: Sage Publications, 2007.

EISENSTADT, Shmuel. Multiple modernities. Daedalus, v.129, n.1, 1-30, 2000.

EUROSTAT. Disponível em: http://ec.europa.eu/eurostat/data/database. Acesso em 31 jul 2018.

GRIM, Brian; FINKE, Roger. International Religion Indexes: Government Regulation, Government Favoritism, and Social Regulation of Religion. Interdisciplinary Journal of Research on Religion, v.2, n.1, 1-40, 2006.

HABERMAS, Jürgen. Between Naturalism and Religion: philosophical essays. Trad. Ciaran Cronin, Cambridge: Polity, 2008.

HALIKIOPOULOU, Daphne. Patterns of Secularization: Church, State and Nation in Greece and the Republic of Ireland. Farnham: Ashgate, 2011.

MARÔCO, João. Análise Estatística com o SPSS Statistics, $7^{a}$ ed. Pêro Pinheiro: ReportNumber, 2018.

MARÔCO, João; GARCIA-MARQUES, Teresa. Qual a fiabilidade do alfa de Cronbach? Questões antigas e soluções modernas?. Laboratório de Psicologia, v.4, n.1, 65-90, 2006.

MARTIN, David. On Secularization: Toward a Revised General Theory. Burlington, Vt.: Ashgate, 2005.

MONIZ, Jorge Botelho. "A secularização na ultramodernidade católica européia: uma proposta de análise contextual e multidimensional do fenômeno da secularização". Em Tese, v.13, n.1, 188219, 2016.

MONIZ, Jorge Botelho. Múltiplas modernidades, múltiplas secularizações e secularização contextual: novas perspectivas sobre o estudo sociológico da religião. Religião \& Sociedade, v.37, n.3, 125-149, 2017.

MONIZ, Jorge Botelho. As camadas internas da secularização: proposta de sistematização de um conceito essencialmente contestado. Sociologia: Revista da Faculdade de Letras da Universidade do Porto, v.34, 73-92, 2017b.

MONIZ, Jorge Botelho. Índice de Religiosidade: Uma proposta de teorização e medição dos fenómenos religiosos contemporâneos. Revista Brasileira de História das Religiões, v.11, n.32, 2018 (no prelo).

NORRIS, Pippa; INGLEHART, Ronald. Sacred and Secular: Religion and Politics Worldwide. Cambridge: Cambridge University Press, 2004.

OCDE - Organização para a Cooperação e Desenvolvimento Económico. Disponível em: https://data.oecd.org/. Acesso em 31 jul 2018. 
PICKEL, Gert. Contextual secularization. Theoretical thoughts and empirical implications. Religion and Society in Central and Eastern Europe, v.4, n.1, 3-20, 2011.

PICKEL, Gert. Secularization - an empirically consolidated narrative in the face of an increasing influence of religion on politics. Política \& Sociedade, v.36, n.16, 259-294, 2017.

UNDP - United Nations Development Programme. Disponível em: http://hdr.undp.org/en/data. Acesso em 31 jul 2018.

WHO - World Health Organization. Disponível em: http://www.who.int/gho/en/. Acesso em 31 jul 2018.

WOHLRAB-SAHR, Monika; BUCHARDT, Marian. Multiples Secularities: Toward a cultural sociology of secular modernities. Comparative Sociology, v.11, 875-909, 2012.

WOHLRAB-SAHR, Monika; BUCHARDT, Marian. Revisitando o secular: secularidades múltiplas e trajetórias para a modernidade. Política \& Sociedade, v.16, n.36, 143-173, 2017.

WORLD BANK OPEN DATA. Disponível em: https://data.worldbank.org/. Acesso em 31 jul 2018. 